\title{
THE
}

\section{Second-mode internal tides in the East China Sea deduced from historical hydrocasts and a model}

\author{
Jae-Hun Park \\ University of Rhode Island \\ Magdalena Andres \\ University of Rhode Island \\ Paul J. Martin \\ Mark Wimbush \\ University of Rhode Island, mwimbush@uri.edu \\ D. Randolph Watts \\ University of Rhode Island, randywatts@uri.edu
}

Follow this and additional works at: https://digitalcommons.uri.edu/gsofacpubs

Terms of Use

All rights reserved under copyright.

\section{Citation/Publisher Attribution}

Park, J.-H., Andres, M., Martin, P. J., Wimbush, M., and Watts, D. R. ( 2006), Second-mode internal tides in the East China Sea deduced from historical hydrocasts and a model, Geophys. Res. Lett., 33, L05602, doi: 10.1029/2005GL024732.

Available at: https://doi.org/10.1029/2005GL024732

This Article is brought to you for free and open access by the Graduate School of Oceanography at DigitalCommons@URI. It has been accepted for inclusion in Graduate School of Oceanography Faculty Publications by an authorized administrator of DigitalCommons@URI. For more information, please contact digitalcommons-group@uri.edu. 


\title{
Second-mode internal tides in the East China Sea deduced from historical hydrocasts and a model
}

\author{
Jae-Hun Park, ${ }^{1}$ Magdalena Andres, ${ }^{1}$ Paul J. Martin, ${ }^{2}$ Mark Wimbush, ${ }^{1}$ \\ and D. Randolph Watts ${ }^{1}$ \\ Received 22 September 2005; revised 10 January 2006; accepted 27 January 2006; published 1 March 2006.
}

[1] From historical hydrocasts in the Okinawa Trough region of the East China Sea (ECS), acoustic echo time from 700 dbar to the surface shows a tight relationship with temperature $(T)$ except near the 100-200-dbar layer. This is caused by 2 nd- or higher-mode baroclinic variations. Significant out-of-phase correlation between upper and lower layer $T$ from the hydrocasts confirms that 2nd-mode variations are strong. Furthermore, the 2 nd-mode variations are dominant during the ebb tide period, which suggests they are caused by 2nd-mode internal tides (ITs) generated at the continental shelf break. For comparison, we investigate historical hydrocasts southeast of the Ryukyu Islands, where no significant 2nd-mode variations are found. A model simulating the $\mathrm{M}_{2}$ IT agrees qualitatively with these observations: it predicts relatively strong 2ndmode IT energy in the ECS, but weak energy in the region southeast of the Ryukyu Islands. Citation: Park, J.-H., M. Andres, P. J. Martin, M. Wimbush, and D. R. Watts (2006), Second-mode internal tides in the East China Sea deduced from historical hydrocasts and a model, Geophys. Res. Lett., 33, L05602, doi:10.1029/2005GL024732.

\section{Introduction}

[2] The East China Sea (ECS) shelf slope has been predicted to be the second strongest $\mathrm{M}_{2}$ internal tide (IT) generation region among the world's continental shelf slopes [Baines, 1982]. Strong IT generation in this region has been confirmed by observations and numerical models [e.g., Kuroda and Mitsudera, 1995; Niwa and Hibiya, 2004]. Kuroda and Mitsudera [1995] observed the detailed structure of ITs in the ECS using an underwater sliding vehicle. In particular, they found abundant evidence of 2ndmode IT structures at the shelf break in the central ECS $\left(29^{\circ} \mathrm{N}, 127.5^{\circ} \mathrm{E}\right)$ during ebb tide periods. They showed that this observation was consistent with Hibiya's [1986] model since the barotropic tidal current was faster (slower) than the phase speed of the 2nd-mode (1st-mode) ITs on the shelf, and hence ebb tides were optimal for the generation of 2 ndmode ITs in the ECS.

[3] During 2002-2004, an array of 11 pressure-sensorequipped inverted echo sounders (PIESs), was deployed on two Kuroshio-transects lines (Figure 1) to observe Kuroshio variability in the ECS. The PIESs measured hourly bottomto-surface acoustic echo time $(\tau)$ and bottom pressure

\footnotetext{
${ }^{1}$ Graduate School of Oceanography, University of Rhode Island, Narragansett, Rhode Island, USA.

${ }^{2}$ Naval Research Laboratory, Stennis Space Center, Mississippi, USA.
}

Copyright 2006 by the American Geophysical Union. 0094-8276/06/2005GL024732 during the two-year deployment period. To obtain temperature $(T)$ and specific volume anomaly $(\delta)$ profiles from $\tau$ and sea surface temperature (SST), observed respectively by PIES and satellite, we constructed multi-index gravest empirical mode (MI-GEM) fields [Park et al., 2005] using historical hydrocasts. However, comparison between the MI-GEM fields and the historical hydrocasts reveals that the MI-GEM fields fail to capture $44 \%$ and $52 \%$ of the $T$ and $\delta$ variance, respectively, in the $p=100-200$-dbar layer. This may be caused by 2 nd- or higher-mode variations of vertical structure, since $\tau$ is insensitive to all but the lowest baroclinic mode [Watts and Rossby, 1977].

[4] In this study, we demonstrate that 2nd-mode ITs in the ECS are responsible for failure of the MI-GEM fields to capture adequately $T$ and $\delta$ variations in the $p=100-200$-dbar layer as seen in historical hydrographic measurements. We verify our observations with a numerical simulation of ITs.

\section{Data and Methods}

[5] We used 1392 historical hydrocasts collected in the ECS from 1929 to 2003, as shown in Figure 1. The data were from the North Pacific Hydrobase [Macdonald et al., 2001] and the Nagasaki Marine Observatory (NMO), Japan Meteorological Agency, and duplicate data were removed. We constructed the MI-GEM fields (not shown here) for $T$ and $\delta$ as functions of $\tau_{700}$, sea surface temperature (SST), and $p$, where $\tau_{700}$ is $\tau$ from the $700-$ dbar level to the surface. To test the MI-GEM representation, we calculated percent variance captured by the MI-GEM fields for $T$ and $\delta$ as a function of pressure for each of these two variables [Watts et al., 2001].

[6] We used sea level (SL) data at Naha, Okinawa (red square in Figure 1) to investigate the time-varying IT energy. The SL data were obtained from the Japan Oceanographic Data Center through their Web site. Larsen et al. [1985] showed that the $\mathrm{M}_{2}$ tide is dominant in the ECS and flows normal to the continental shelf. From the $\mathrm{M}_{2}$ tidal chart by Niwa and Hibiya [2004], the tidal phase difference between Naha and the Okinawa Trough region is within $15^{\circ}$ $(\sim 0.52 \mathrm{~h})$. Since precise observation times are given for NMO hydrocasts from 1987 to 2003, we could separate them into two groups: flood tide period (from 2.5 hours after low tide to 2.5 hours after high tide) and ebb tide period (from 2.5 hours after high tide to 2.5 hours after low tide), based on the $\mathrm{M}_{2}$ tide SL at Naha. For each group, we calculated the correlation coefficients between 120-dbar $T$ $\left(T_{120}\right)$ and $T$ at other depths to investigate the possible relation between $T$ variation and the ECS tide. For comparison, we did the same calculation with NMO hydrocasts from the region southeast of the Ryukyu Islands. 


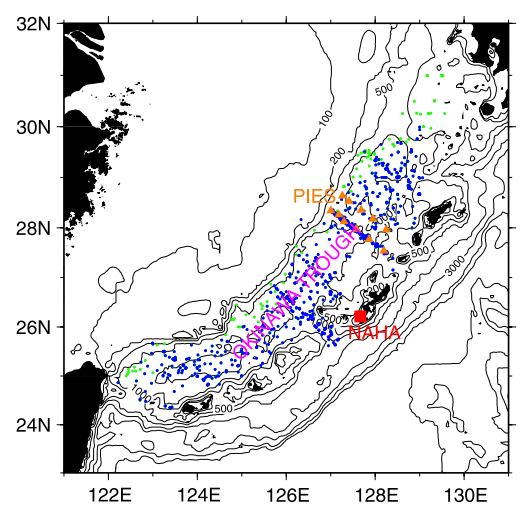

Figure 1. The East China Sea and adjacent seas. Orange triangles indicate PIES sites and red square Naha coastal tide gauge. Blue and green dots are hydrocasts with $\tau_{700} \leq$ $0.924 \mathrm{~s}$ and $>0.924 \mathrm{~s}$, respectively. Bathymetry contours are in meters.

[7] The ocean model used in this study is the Navy Coastal Ocean Model (NCOM) as described by Martin [2000]. This model is similar in its physics and numerics to the Princeton Ocean Model [Blumberg and Mellor, 1987], but uses an implicit treatment of the free surface. The hydrostatic assumption of the NCOM is not valid in small horizontal scales, but the ITs we focus on have relatively large horizontal scales and should not be significantly affected by this assumption. For the numerical simulations conducted here, the model domain covered $121-131^{\circ} \mathrm{E}, 23-32^{\circ} \mathrm{N}$ with horizontal grid resolution of about $2.9 \mathrm{~km}$. The vertical grid was $\sigma$-coordinate with 40 layers, a uniform stretching in the vertical, and a maximum depth of $5500 \mathrm{~m}$. The initial $T$ and salinity $(S)$ were from Levitus climatology, horizontally averaged over the model domain. Radiation conditions were used at the open boundaries. The $\mathrm{M}_{2}$ barotropic tide was forced with elevations and velocities at the open boundaries from the Oregon State University global tide database [Egbert and Erofeeva, 2003] and tidal potential forcing over the interior. The model was run for 20 days with a 200 s timestep. The model output used here consisted of hourly values subsampled once every four grid points along the zonal and meridional directions during the last 7 days.

[8] We investigated the spatial distribution of the 1st- and 2nd-mode $\mathrm{M}_{2}$ IT energy using the following procedure at each subsampled grid point of the IT model. Firstly, fluctuation of $T$ was converted into vertical displacement

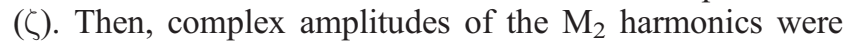
calculated for $\zeta$ and horizontal baroclinic velocity components $(u, v)$. Secondly, a modal decomposition of the first 5 vertical modes was calculated using the initial $T$ and $S$, and the model bottom depth $(H)$. Then, the calculated modal functions were least-squares fitted to the $\mathrm{M}_{2}$ harmonics of $u$, $v$, and $\zeta$. Finally, using the first 2 modes, we calculated the depth-integrated 1st- and 2nd-mode potential and kinetic IT energy densities given by [Merrifield and Holloway, 2002]

$$
\begin{aligned}
& E p_{n}=\frac{1}{4} \int_{-H}^{0} \rho_{0}\left[N^{2}\left|\zeta_{n}\right|^{2}\right] d z, \quad \text { and } \\
& E k_{n}=\frac{1}{4} \int_{-H}^{0} \rho_{0}\left[\left|u_{n}\right|^{2}+\left|v_{n}\right|^{2}\right] d z,
\end{aligned}
$$

respectively, where $n$ is the mode number and $\rho_{0}$ the initial vertical mean density.

\section{Results}

[9] Figure 2a shows the percent variance captured by the MI-GEM fields for $T$ and $\delta$ as a function of pressure. Averaged through the depth range from 100 to $200 \mathrm{dbar}$, MI-GEM captures only $56 \%$ and $48 \%$ of the variances for $T$ and $\delta$, respectively. Figures $2 \mathrm{~b}$ and $2 \mathrm{c}$ show scatter plots of $\tau_{700}$ vs. $T_{120}$ and $\tau_{700}$ vs. $T_{400}$, respectively, where $T_{400}$ is temperature at the 400 -dbar level. Figures $2 \mathrm{~b}$ and $2 \mathrm{c}$ reveal that $\tau_{700}$ has a tight relation with $T_{400}$, but not with $T_{120}$, especially when $\tau_{700}$ is less than $0.924 \mathrm{~s}$ (blue dots in Figure 1). This results in the low value of percent variance captured around 100-200 dbar in Figure 2a. The unrepresented $T$ and $\delta$ variations in the 100-200-dbar layer are presumably from 2nd- or higher-mode baroclinic variations, since $\tau_{700}$ is insensitive to all but the lowest baroclinicmode vertical structure, and the effects of SST variation do not reach deeper than about $p=100 \mathrm{dbar}$ in the ECS.

[10] Figure 3 shows the correlation coefficients $(r$, solid line) between $T_{120}$ and $T_{p}$ with $p$ between 0 and $700 \mathrm{dbar}$ for all historical hydrocasts with $\tau_{700} \leq 0.924 \mathrm{~s}$ (gray-shaded zone in Figure 2b) in the ECS. The $r$ shows a significant out-of-phase correlation between layers above and below $\sim 300$ dbar, which suggests that 2 nd vertical-mode variation is dominant in this region. For comparison, Figure 3 also exhibits the vertical structure of $T$ fluctuation, $\mathrm{T}^{\prime}$ (blue lines), caused by the normalized $\zeta$ of 2 nd-mode ITs with a maximum amplitude of $1 \mathrm{~m}$ calculated from modal decomposition using the mean profile of historical hydrocasts with $\tau_{700} \leq 0.924 \mathrm{~s}$ and bottom depths from 700 to $1300 \mathrm{dbar}$ at 100-dbar intervals. The vertical structures of calculated $\mathrm{T}^{\prime}$ are all consistent with the observed out-of-
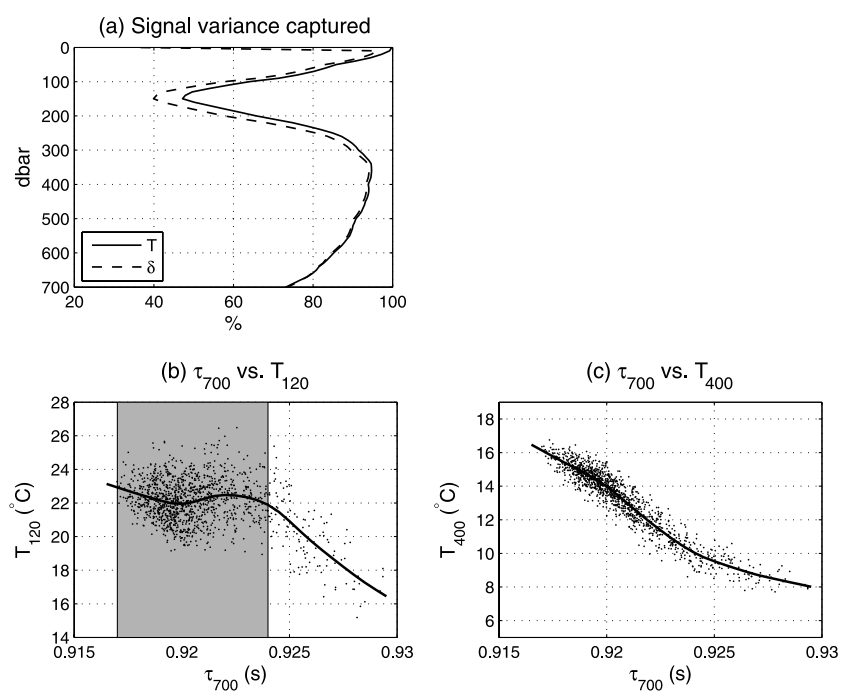

Figure 2. (a) Signal variance percentage of total variance for $T$ and $\delta$ computed from the MI-GEM fields in the ECS. (b) Scatter plot of $\tau_{700}$ vs. $T_{120}$. Gray-shaded zone indicates highly-scattered hydrocasts $(\leq 0.924 \mathrm{~s}$, blue dots in Figure 1) used for correlation coefficient calculation in Figure 3. (c) Scatter plot of $\tau_{700}$ vs. $T_{400}$. Thick lines in Figures $2 \mathrm{~b}$ and $2 \mathrm{c}$ are cubic smoothing spline-fitted curves. 


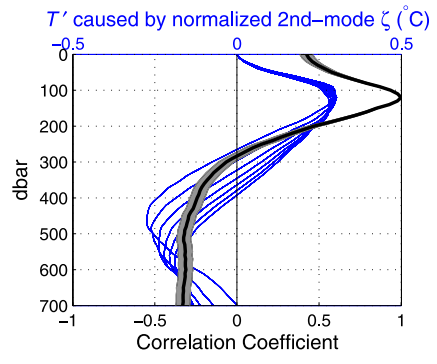

Figure 3. Correlation coefficients between $T_{120}$ and $T$ at other pressure levels using historical hydrocasts with $\tau_{700} \leq$ $0.924 \mathrm{~s}$ (gray-shaded zone in Figure 2b) in the ECS. Grayshaded zone indicates $90 \%$ confidence intervals for the calculated correlation coefficients. Blue lines indicate $T$ fluctuation $\left(\mathrm{T}^{\prime}\right)$ caused by normalized vertical displacement $(\zeta)$ of 2nd-mode ITs calculated from modal decomposition using the mean profile of historical hydrocasts $\left(\tau_{700} \leq\right.$ $0.924 \mathrm{~s}$ ) and bottom depths from 700 to $1300 \mathrm{dbar}$ at 100 dbar intervals.

phase correlation with largest upper-layer $\mathrm{T}^{\prime}$ in the $100-$ 200-dbar layer.

[11] Figure 4 demonstrates how the 2nd-mode variations are related to the tides. The blue and red lines in Figure 4a indicate the flood and ebb tide periods during a cycle of the $\mathrm{M}_{2}$ tide at Naha. Figure $4 \mathrm{c}$ shows the $r$ between $T_{120}$ and $T_{p}$ with $p$ values from 0 to $700 \mathrm{dbar}$, for the flood (blue line) and ebb (red line) tide period hydrocast groups in the ECS
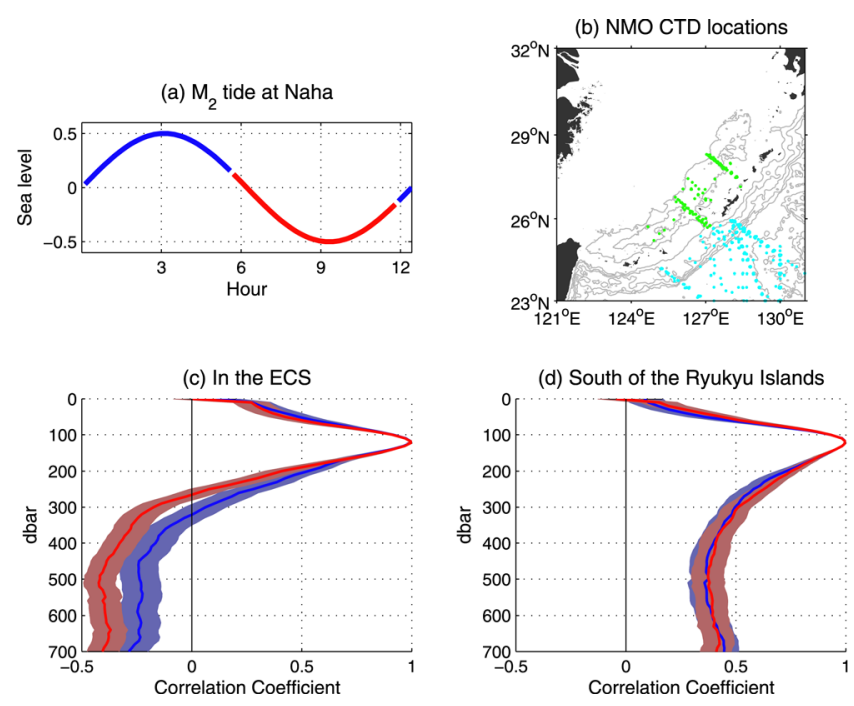

Figure 4. (a) $\mathrm{M}_{2}$ tidal elevation at Naha coastal tide gauge station. Red and blue lines indicate ebb and flood tide periods, respectively (see text for details). (b) Location map of the NMO CTDs in the ECS (green dots) and south of the Ryukyu Islands (cyan dots). (c) Correlation coefficients between $T_{120}$ and $T$ at other depths using the hydrocasts with $\tau_{700} \leq 0.924$ s collected in the ECS by NMO (green dots in Figure 4b). (d) Same as Figure 4c except in the region south of the Ryukyu Islands (cyan dots in Figure 4b). Red and blue lines in Figures $4 \mathrm{c}$ and $4 \mathrm{~d}$ indicate ebb and flood tide period hydrocasts, respectively. Red- and blueshaded zones indicate $90 \%$ confidence intervals for the calculated correlation coefficients.
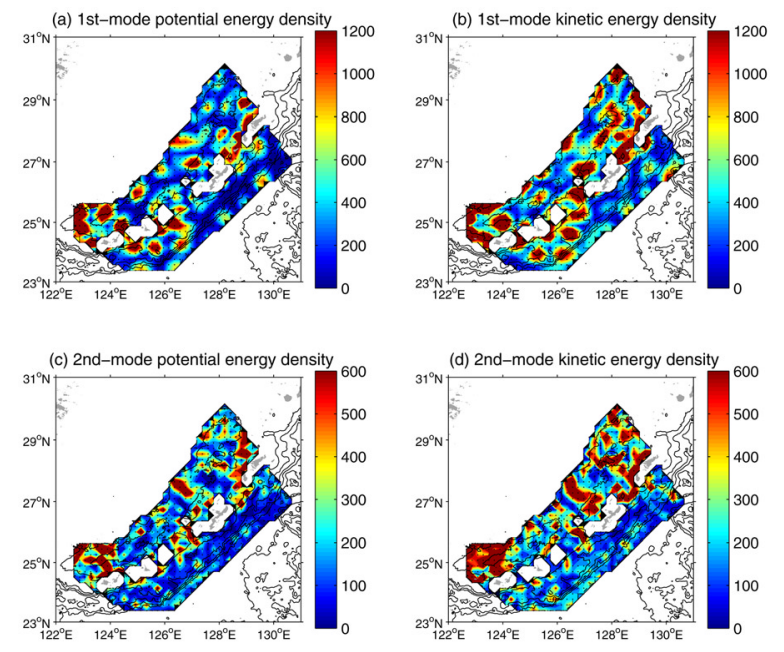

Figure 5. (left) Potential and (right) kinetic energy density $\left(\mathrm{Jm}^{-2}\right.$ ) for the (top) 1st-mode and (bottom) 2nd-mode $\mathrm{M}_{2}$ ITs computed using the model output.

(green dots in Figure 4b). We use hydrocasts with $\tau_{700} \leq$ $0.924 \mathrm{~s}$, which consist of 323 and 368 casts for the flood and ebb tide periods, respectively. The $r$ values show stronger 2nd-mode correlations between the layers above and below $\sim 300$ dbar during the ebb tide period than the flood tide period. For comparison, Figure $4 \mathrm{~d}$ shows $r$ calculated in the region south of the Ryukyu Islands (cyan dots in Figure 4b). We again use hydrocasts with $\tau_{700} \leq$ $0.924 \mathrm{~s}$, which consist of 381 and 382 casts for the flood and ebb tide periods, respectively. No significant 2nd-mode variations are found in this region in either the flood or ebb tide periods. This result suggests that the baroclinic 2ndmode variations observed in the hydrocasts are caused by 2nd-mode ITs generated mainly at the continental shelf break. Higher-mode ITs and 2nd-or-higher-mode shorter time scale internal waves may contribute some part of the observed variations in the 100-200-dbar layer. Nevertheless, Figures 3 and 4 suggest the predominant signal not captured by $\tau_{700}$ arises from 2 nd-mode ITs.

[12] Figure 5 shows the 1st- and 2nd-mode IT energy densities calculated from the NCOM model output. The model predicts dominant 1st-mode IT energy as expected, showing some "hot spots" of energy near the continental shelf and the Ryukyu Islands. The locations of hot spots in our 1st-mode IT kinetic energy distribution (Figure 5b) agree well with those in Niwa and Hibiya's [2004] kinetic IT energy distribution predicted from a numerical simulation. In addition to the dominant 1st-mode energy, our model also predicts strong 2nd-mode IT energy in the ECS. Moreover, although the model predicts strong 1stmode IT energy in the region south of the Ryukyu Islands, it predicts weak 2 nd-mode energy there. These simulation results agree well with our observations.

[13] For detailed comparison between our observations and model output, we calculated $r$ between $T_{150}$ and $T_{p}$ with $p$ values from 0 to $700 \mathrm{dbar}$ using $T$ profiles from the model output in the ECS and south of the Ryukyu Islands, indicated by green and cyan dots (118 and 161 grid points) in Figure 6b, respectively. Figure $6 a$ exhibits flood and ebb tide period grouping of model output based on the tidal elevation at Naha in the model during an $\mathrm{M}_{2}$ tide cycle in 

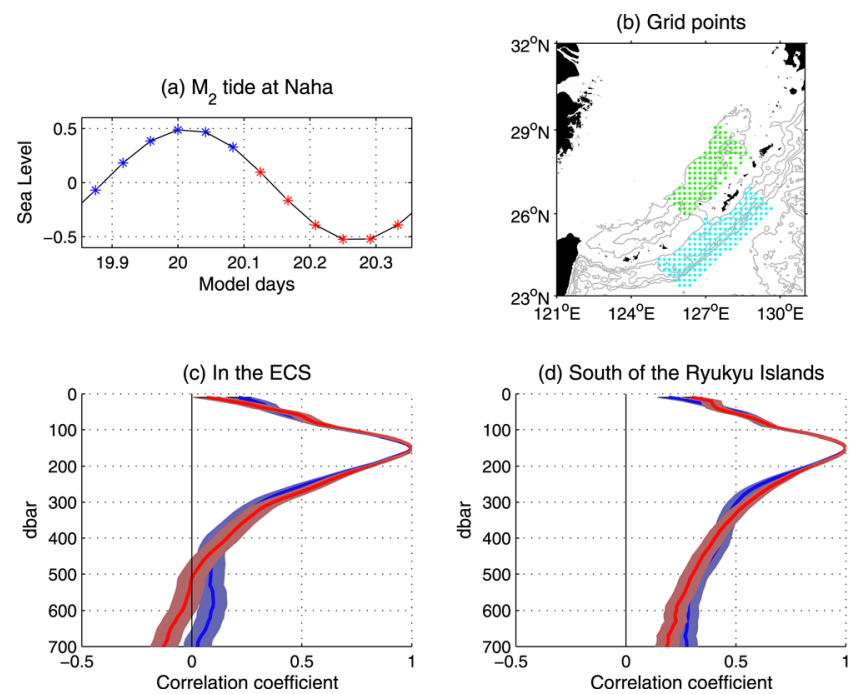

Figure 6. (a) $\mathrm{M}_{2}$ tidal elevation at Naha from IT model. Red and blue asterisks indicate model output time for ebb tide and flood tide periods, respectively. (b) Location map of the model grid points in the ECS (green dots) and south of the Ryukyu Islands (cyan dots), where $T$ profiles are used for correlation coefficient calculations. (c) Correlation coefficients between $T_{150}$ and $T$ at other depths in the ECS (green dots in Figure 6b). (d) Same as Figure 6c except in the region south of the Ryukyu Islands (cyan dots in Figure $6 \mathrm{~b}$ ). Red and blue lines in Figures $6 \mathrm{c}$ and $6 \mathrm{~d}$ indicate ebb and flood tide period model output, respectively. Redand blue-shaded zones indicate $90 \%$ confidence intervals for the calculated correlation coefficients

the last model day. For the flood tide period group, we use hourly $T$ profiles of model output from 21:00 on model day 19 to $02: 00$ on model day 20. For the ebb tide period group, we use those from $03: 00$ to $08: 00$ on model day 20. In Figure 6c, $r$ shows a significant out-of-phase relation between layers above and below $~ 500$ dbar during the ebb tide period, but no such relation during the flood tide period. In Figure 6d, $r$ shows no significant 2nd-mode variations in either the flood or ebb tide periods. These results are qualitatively consistent with our observations, even though the depth of zero-crossing and the $r$ magnitudes differ from those in our observations since the model was run with a simple initial stratification independent of $(\mathrm{x}, \mathrm{y})$.

\section{Conclusion}

[14] In the ECS, the MI-GEM fields fail to capture $44 \%$ and $52 \%$ of $T$ and $\delta$ variations, respectively, in the $p=100-$ 200-dbar layer. These unrepresented variations are shown to be caused by strong 2nd-mode ITs whose signals appear in the hydrographic profiles but not in the acoustic echo time $\tau_{700}$. Using coastal tide gauge data at Naha, we have demonstrated that the 2nd-mode ITs are stronger during the ebb tide period than the flood tide period. The barotropic tidal current speed is close to the phase speed of 2nd-mode ITs at the continental shelf break, optimal for the generation of 2nd-mode ITs [Kuroda and Mitsudera, 1995]. Offshore tidal flow during the ebb tide period can release the generated 2nd-mode ITs into the Okinawa Trough. We have also demonstrated that significant 2 nd-mode variations are not present in the region south of the Ryukyu Islands. The numerical simulation results of a 3-dimensional IT model are qualitatively consistent with these observations.

[15] The principal object of our PIES experiment in the ECS is to study the dynamics of Kuroshio variability with time periods longer than a day. Therefore, it is apparent that even though the MI-GEM fields cannot capture the variations caused by 2 nd-mode ITs, they will provide accurate representations of these subtidal dynamics throughout the water column since the 2nd-mode ITs with semi-diurnal period are responsible for the large errors at $p=100-$ $200 \mathrm{dbar}$ in the MI-GEM fields.

[16] Acknowledgments. We thank Nagasaki Marine Observatory, Japan Meteorological Agency for kindly providing the hydrographic data, and Japan Oceanographic Data Center for making their sea level data publicly available through their Web site. We also thank two anonymous reviewers for their valuable comments on the original manuscript. This work was supported by the Office of Naval Research grant number N000140210271.

\section{References}

Baines, P. G. (1982), On internal tide generation models, Deep Sea Res., 29, 307-338.

Blumberg, A. F., and G. L. Mellor (1987), A description of a three-dimensional coastal ocean circulation model, in Three-Dimensional Coastal Ocean Models, Coastal Estuarine Sci. Ser., vol. 4, edited by N. Heaps, pp. 1-16, AGU, Washington, D. C.

Egbert, G. D., and S. Y. Erofeeva (2003), Efficient inverse modeling of barotropic ocean tides, J. Atmos. Oceanic Technol., 19, 183-204.

Hibiya, T. (1986), Generation mechanism of internal waves by tidal flow over a sill, J. Geophys. Res., 91, 7697-7708.

Kuroda, Y., and H. Mitsudera (1995), Observation of internal tides in the East China Sea with an underwater sliding vehicle, J. Geophys. Res., 100, $10,801-10,816$.

Larsen, L. H., G. A. Cannon, and B. H. Choi (1985), East China Sea tide current, Cont. Shelf Res., 4, 77-103.

Macdonald, A. M., T. Suga, and R. G. Curry (2001), An isopycnally averaged north Pacific climatology, J. Atmos. Oceanic Technol., 18, 394420.

Martin, P. J. (2000), A description of the Navy Coastal Ocean Model version 1.0, NRL Rep. NRL/FR/7322-00-9962, 42 pp., Naval Res. Lab., Stennis Space Cent., Miss.

Merrifield, M. A., and P. E. Holloway (2002), Model estimates of $\mathrm{M}_{2}$ internal tide energetics at the Hawaiian Ridge, J. Geophys. Res., 107(C8), 3179, doi:10.1029/2001JC000996.

Niwa, Y., and T. Hibiya (2004), Three-dimensional numerical simulation of $\mathrm{M}_{2}$ internal tides in the East China Sea, J. Geophys. Res., 109, C04027, doi:10.1029/2003JC001923.

Park, J.-H., D. R. Watts, K. L. Tracey, and D. A. Mitchell (2005), A multiindex GEM technique and its application to the southwestern Japan/East Sea, J. Atmos. Oceanic Technol., 22, 1282-1293.

Watts, D. R., and H. T. Rossby (1977), Measuring dynamic heights with inverted echo sounders: Results from MODE, J. Phys. Oceanogr., 7, $345-358$.

Watts, D. R., C. Sun, and S. Rintoul (2001), A two-dimensional gravest empirical mode determined from hydrographic observations in the Subantarctic Front, J. Phys. Oceanogr., 31, 2186-2209.

M. Andres, J.-H. Park, D. R. Watts, and M. Wimbush, Graduate School of Oceanography, University of Rhode Island, Narragansett, RI 028821197, USA. (jpark@gso.uri.edu)

P. J. Martin, Naval Research Laboratory, Stennis Space Center, MS 39529, USA. 